\title{
Age-related changes in human scalp extracellular matrix-implications for the hair follicle?
}

Rachael Sutherland-Sedman, Gillian E Westgate, Desmond J Tobin, M Julie Thornton

\section{Introduction}

Human skin is routinely used to study age-related changes in structure, gene and protein expression, however ageing in the human scalp still needs further exploration. It is known that facial skin integrity is diminished with age due to intrinsic and extrinsic factors including UV exposure, lifestyle and hormonal changes. Dermal fibroblasts (DFs) are responsible for the production and maintenance of the extracellular matrix (ECM), a network of collagen and elastin fibrils interwoven with proteoglycans. The main age-related changes within the dermis result in alterations to the structure of the ECM. Therefore, we hypothesise that these ECM changes will also influence the hair follicle dermal environment. The aim of this study was to identify age-related changes within adult female hair-bearing scalp dermis with increasing age.

\section{Methods}

Cell culture

Primary cultures of DFs derived from normal healthy female scalp aged 19-81yrs ( $n=12$ ) were Primalished and passaged no more than 3 times. Quantitative-RT-PCR comparisons were made between DFs cultured from women under 40yrs $(n=4)$ and over 40yrs $(n=8)$.

Histology

Cryosections from 13 donors, 12 of which were matched to the QPCR donors, were stained with H\&E and imaged with a Phillip's digital pathology scanner. Changes within structure were noted and where applicable measured (i.e. area of papillary dermis and hair follicle depth) with the Phillip's digital pathology software.

Quantitative RT-PCR

Confluent cultures of DFs were harvested from T75 flasks, with RNA extracted and converted to DNA. Expression of mRNA was calculated as the relative gene expression in relation to the housekeeping gene RPS18 and analysed using the 2- $\triangle \triangle C T$ (Livak) Method. Statistical Analysis

Statistical analysis was conducted using PRISM software. For the comparison of under 40yrs vs. over 40yrs the Mann Whitney T-test was used with a level of significance $p<0.05$.

\section{The ageing hair follicle environment}

Female age 20

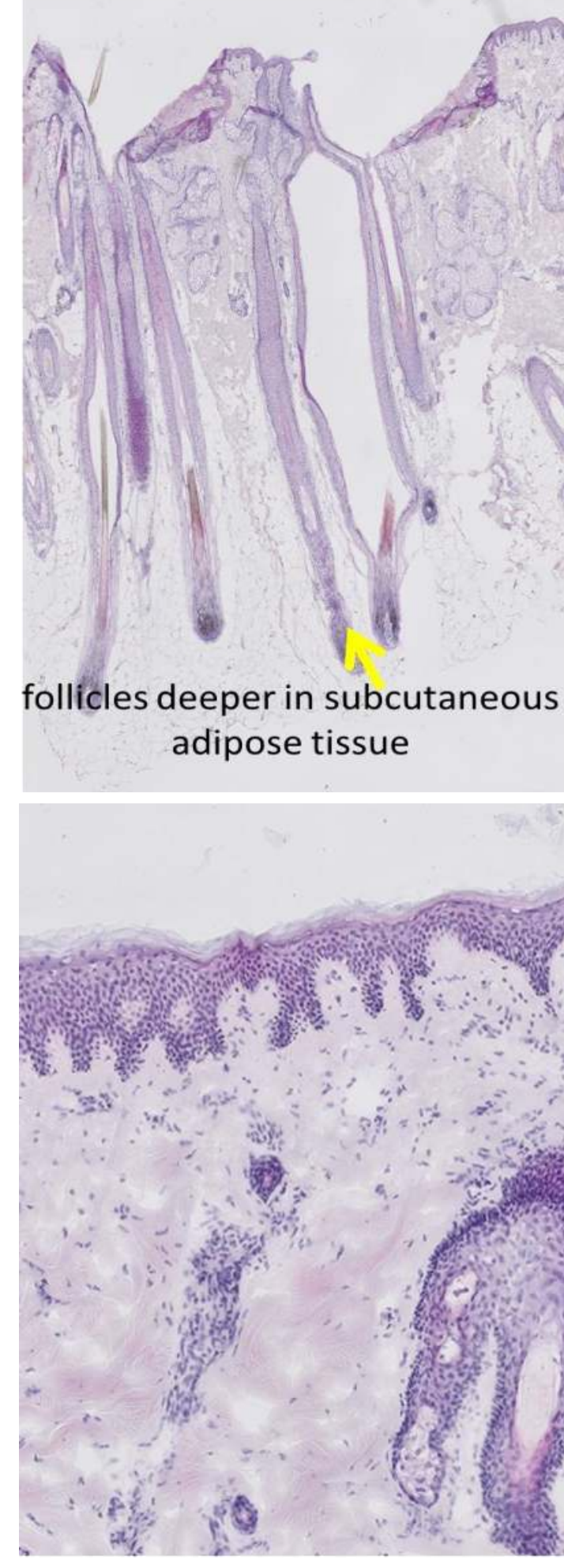

Female age 21 years
Female age 81

papillary \& reticular dermis

distinct

follicles not as deep

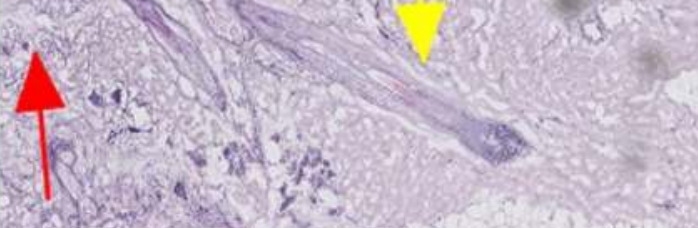

disorganised fibrils

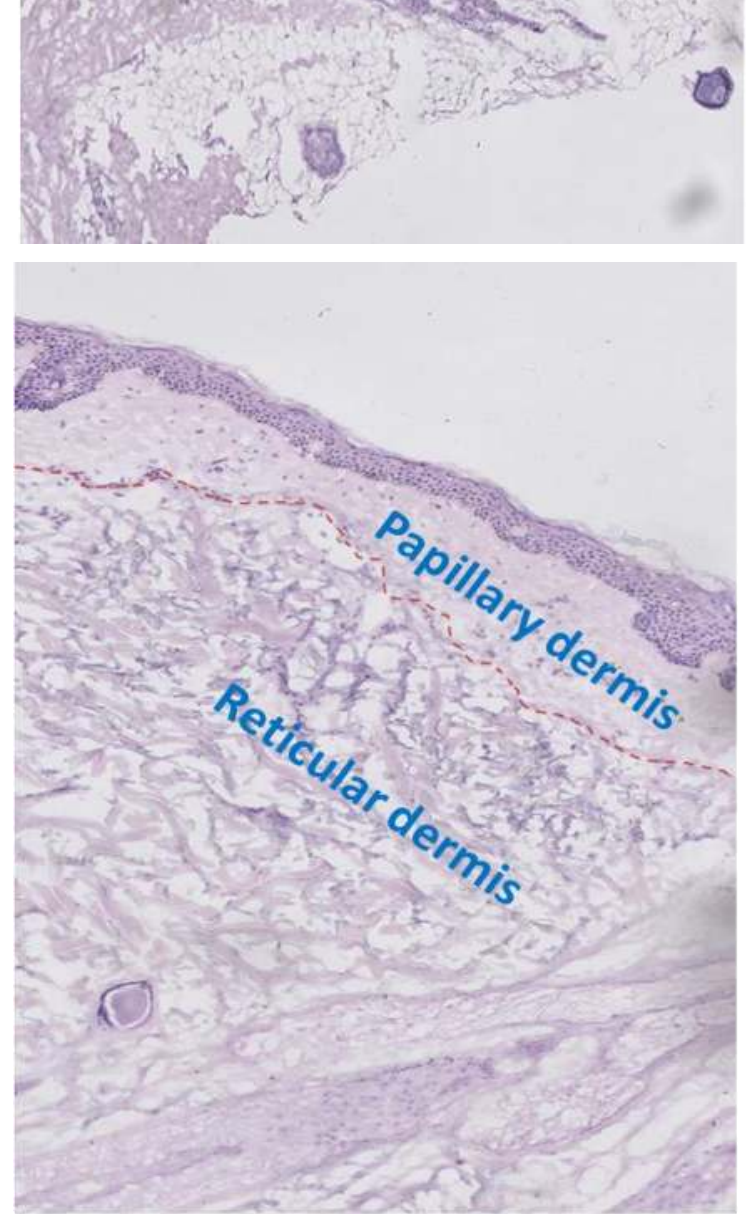

Female age 81 years
A flatter epidermal-dermal junction with less prominent rete ridges was seen in scalp with increasing age. The papillary \& reticular dermis was indistinct under 40yrs $(n=4)$ but clearly distinguishable over $40 y r s(n=9)$. Hair follicles appeared to penetrate deeper into the subcutis scalp from the younger group, whereas with age the collagen fibrils appeared disorganised.

\section{Changes in DF ECM biomarkers with age}

\begin{tabular}{ccc}
$\begin{array}{c}\text { Biomarker } \\
\text { (mRNA) }\end{array}$ & Associated function & Change with age \\
MMP1 & $\begin{array}{c}\text { Increased levels associated with } \\
\text { fragmented and dissociated collagen } \\
\text { fibrils }\end{array}$ & $\begin{array}{c}\text { Increases with age } \\
\text { p<0.05 between under } 60 \text { and over } 60 \text { age } \\
\text { groups }\end{array}$ \\
\hline MMP9 & $\begin{array}{c}\text { Increased levels associated with elastin \& } \\
\text { collagen degradation }\end{array}$ & No difference \\
TIMP1 & Maintains homeostasis of ECM & No difference
\end{tabular}

Collagen XVI Connects ECM proteins to cells - ensure

Decreases with age mechanical anchorage $P<0.05$ between under 40 s and over 40

Versican (VCAN)

Proteoglycan disappears from the dermal papilla in androgenetic alopecia

Decreases with age

Hyaluronic acid synthase type 2 HAS2

Enzyme responsible for synthesis of the proteoglycan hyaluronic acid

Decreases with age

Protease nexin1

(Serpine 2)

evels in dermal papilla cells are reduced by $5 \alpha$-dihydrotestosterone

Decreases with age $P<0.05$ between under 40 s and over 40 s

\section{Cartilage oligomeric \\ matrix protein (COMP)}

Cysteine-rich protein 61 (CYR61)

Lysyl oxidase -like protein 2 (LOXL2)

A glycoprotein that functions as an adaptor protein organizing collagen fibrils

No difference

Elevated levels inhibit collagen I and III synthesis

Important in the biosynthesis and renewal of elastic tissue

o difference

Integrin

Important in remodelling of ECM and also transducing signals to cells

o difference

\begin{tabular}{ccc} 
Integrin & $\begin{array}{c}\text { Important in remodelling of ECM and also } \\
\text { transducing signals to cells }\end{array}$ & No difference \\
\hline $\begin{array}{c}\text { Kallistatin } \\
\text { (Serpina 4) }\end{array}$ & $\begin{array}{c}\text { A serine protease inhibitor that has anti- } \\
\text { inflammatory effects }\end{array}$ & $\begin{array}{c}\text { Not present in any of the samples } \\
\text { (confirmed with a positive primer control) }\end{array}$ \\
\hline
\end{tabular}

\section{Significant alterations in ECM}

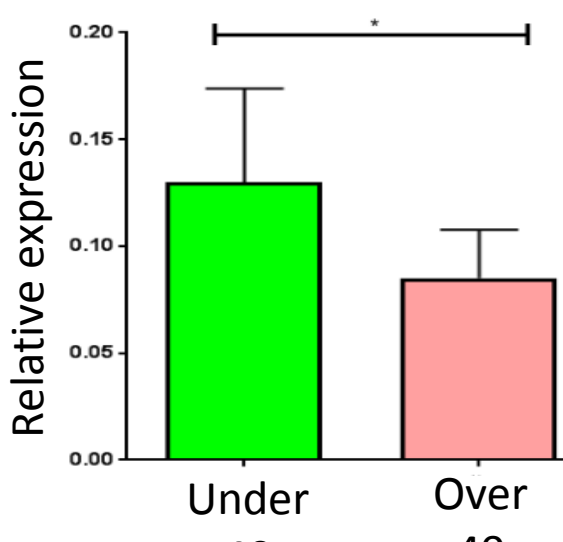
gene expression with age MMP1

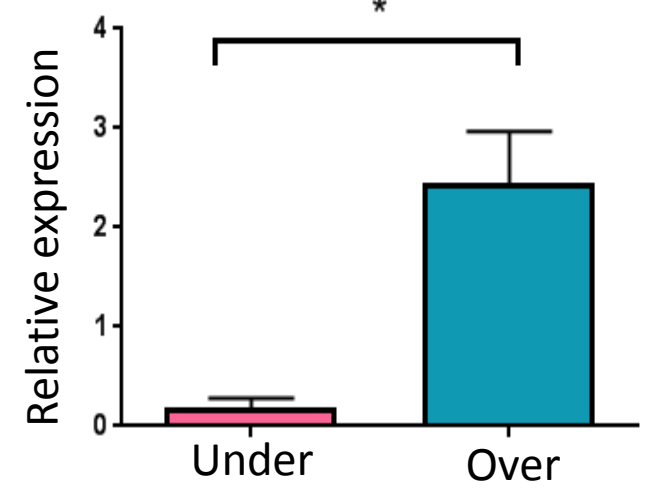

Collagen XVI

60

60

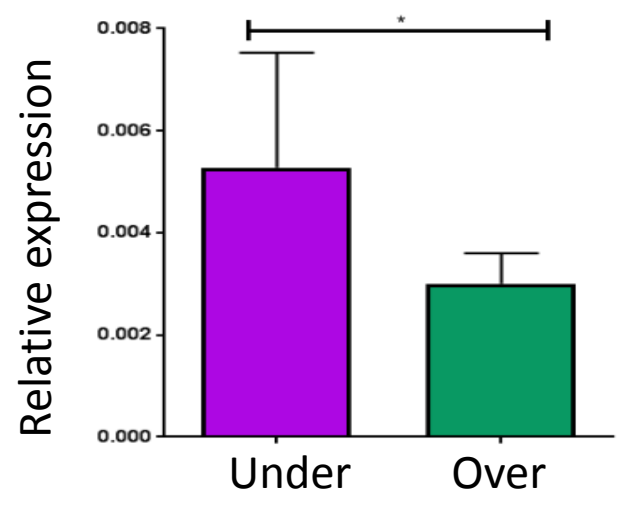

40

Protease nexin-1

Hyaluronan synthase 2

Versican

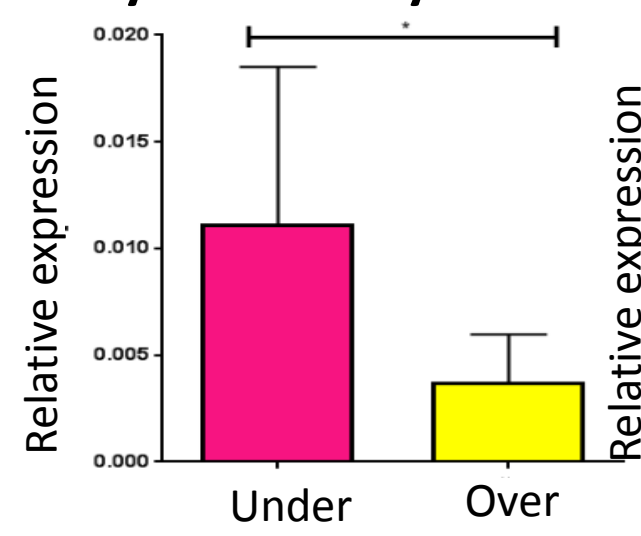

40

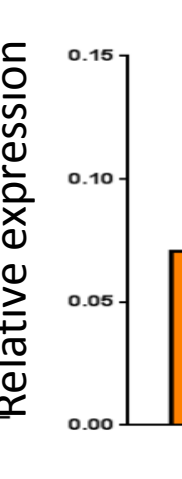

Under

40

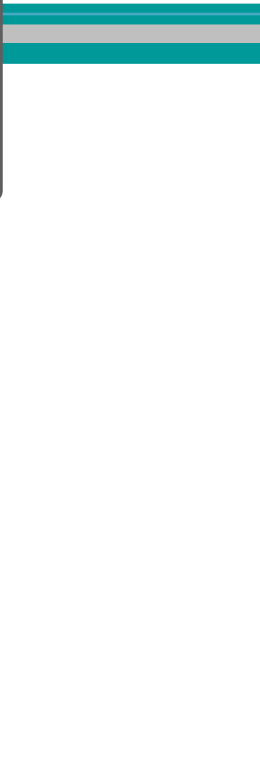

Quantitative RT-PCR comparing the mRNA expression of MMP1 in cultured human female scalp DFs from two different age groups; 19-59yrs $(n=7)$ and 60-81yrs $(n=5)$. The mRNA expression of Collagen XVI, Versican, Hyaluronan synthase 2, Protease nexin-1 was compared in cultured human female scalp DFs from two different age groups; $19-38 y r s(n=4)$ and $43-81 y r s(n=8)$. All were assayed between passage 0 and 3 . two different

\section{Conclusion}

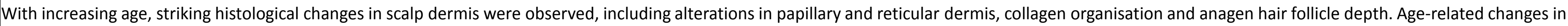

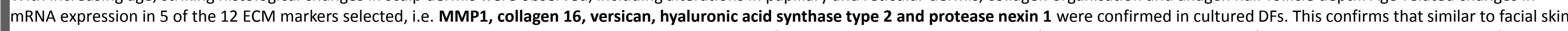

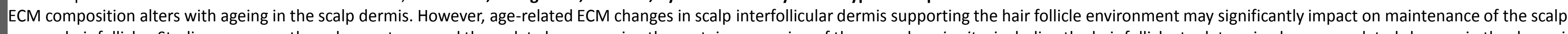

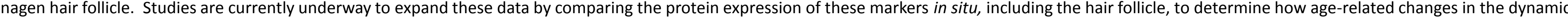
dermal environment impact on the ageing hair follicle. 